\title{
Robert Castel discute a discriminação negativa na França multicultural
}

\section{Simone da Silva Ribeiro Gomes*}

Mestranda do Programa de Pós-Graduação em Psicologia Social da Universidade do Estado do Rio de Janeiro - UERJ, Rio de Janeiro, RJ, Brasil

\section{Ana Lucia Gonçalves Maiolino**}

Professora Visitante do Programa de Pós-Graduação em Psicologia Social e do Instituto de Psicologia da Universidade do Estado do Rio de Janeiro - UERJ, Rio de Janeiro, RJ, Brasil

\section{A DI SCRI MI NAÇÃO NEGATI VA : CI DADÃOS OU AUTÓCTONES? CASTEL, Robert. (136 p) La discrimination négative : citoyens ou indigènes? Tradução Francisco Moras \\ Petrópolis, RJ: Vozes, 2008.}

A obra "A discriminação negativa: cidadãos ou autóctones", de Robert Castel, editada na França em 2007 e traduzida para o português em 2008, discute a discriminação negativa, que atinge jovens moradores das periferias urbanas francesas. Um mecanismo que se explicita em tempos multiculturais e multiétnicos, quando se evidencia que tais jovens, com origem popular e preponderantemente provenientes da imigração africana, "acumulam uma série de contra-performances sociais" (p. 10), vivenciando a precariedade, a economia informal e, por vezes, a delinqüência. Para Castel, ser discriminado negativamente representa estar associado a um estigma, que os transforma em símbolos da inutilidade social e da periculosidade.

Como fio condutor, o autor se utiliza dos acontecimentos ocorridos na França, em 2005, que ficaram conhecidos como a "revolta dos jovens franceses do subúrbio" (ou "I' banlieu s' exprime" algo como "a periferia se exprime), momento em que jovens moradores destas zonas periféricas iniciaram episódios de violência em toda a cidade de Paris. Para Castel, tais episódios, desprovidos de reivindicações e marcados por intervenções improvisadas e esporádicas, constituíram-se como uma forma de demonstrar seu descontentamento com o tratamento recebido 
pela sociedade francesa como um todo, em face de um profundo sentimento de desesperança que perpassa suas expectativas em relação a conseguirem uma pertença plena à sociedade e a suas perspectivas futuras.

Neste sentido, apesar de o trabalho de Castel centrar sua análises especificamente no caso francês, suas análises detalhadas e hipóteses explicativas podem ser utilizadas no estudo de outras tantas situações discriminatórias vividas por habitantes das periferias mundo afora, inclusive no Brasil.

O primeiro capítulo do livro mapeia a evolução desses espaços urbanos periféricos. Se atualmente são consideradas lugares de abandono, ou como nos eufemismos oficiais "bairros sensíveis, na década de 50 , seus grandes conjuntos habitacionais constituíam-se como solução aos graves problemas habitacionais, sendo marcados pela revolução na forma de habitar a cidade. Na década de 70, também se estabelecem como local de acolhida privilegiada a famílias de imigrantes. No entanto, na França contemporânea, marcadas pelo duplo processo de etnização e pauperização, sua imagem se degrada.

A pauperização que atinge não apenas estas áreas, mas o país como um todo, decorre da escalada do desemprego, da ocorrência dos empregos precários e da pobreza desencadeadas pelo capitalismo atual. Já a etnização provém da imigração, que, acompanhada deste quadro na esfera do trabalho, acaba por transformar "tais locais em praticamente a única opção de alojamento, estabelecendo-se como uma espécie de prisão domiciliar" (p. 23)

Tendo este cenário territorial como pano de fundo, Castel, no segundo capítulo, aborda a vivência "nas margens" destes jovens, destacando que, se não estão confinados a guetos (como os negros norteamericanos nas grandes cidades dos EUA), não vivenciam uma situação de apartheid e também não conhecem a miséria, por outro lado, não ocupam nenhum lugar reconhecido, tendo um cotidiano marcado por promessas não cumpridas em relação a oportunidades e valores encarnados pela sociedade francesa. Assim, apesar de se beneficiarem de prerrogativas essenciais de pertença à nação francesa, dispondo de cidadania política e social, recebem um tratamento que os desqualifica. O que difere na gestão nacional dessas minorias étnicas é justamente o mote do terceiro capítulo. Castel evidencia sua inserção precária em diferentes aspectos da vida social: no campo do trabalho, na relação com a polícia e a justiça, na escola, que, somados à crescente ojeriza pelo Islamismo no país, evidenciam um quadro de desvantagens concretas.

Desta forma, o autor conclui que, apesar de não estarem excluídos, 
também não podem ser considerados incluídos:

(...) o problema com o qual se defrontam estes jovens não é estar fora da sociedade, nem quanto ao espaço que ocupam [...], nem quanto ao estatuto deles (muitos são cidadãos e não estrangeiros). Contudo, eles também não estão dentro, visto que não ocupam nenhum lugar reconhecido e muitos dentre eles parecem pouco suscetíveis de encontrar este espaço. (p.40)

Castel destaca que esse déficit de cidadania, e o respectivo sentimento de injustiça vivenciado pelos jovens, é ainda mais grave se considerarmos que estamos em presença de uma sociedade que clama pela igualdade de direitos e chances.

No quarto capítulo, Castel analisa o fato de estes jovens, "a partir da desqualificação da qual são objeto, transformarem-se em receptáculos privilegiados na cristalização dos temores que atravessam o conjunto da sociedade". Uma tendência que "cristaliza nas margens as rachaduras do centro" e responsabiliza pelas "disfunções aqueles que são justamente suas maiores vítimas" (p. 59-60).

Utilizando-se da insegurança como exemplo deste quadro, Castel questiona o fato de as minorias serem tomadas, praticamente, como as únicas responsáveis por todo o problema, "de sorte que a erradicação da periculosidade que elas trazem estaria, em última instância, impondo uma vitória à insegurança generalizada" (p. 65).

Dentro deste contexto, o autor observa que os acontecimentos de 2005 podem evidenciar o lugar que ainda ocupa, na sociedade francesa, a discriminação etnorracial, apesar dos avanços da Constituição em relação ao passado colonialista da nação.

$\mathrm{Na}$ busca de uma construção explicativa a esta discriminação etnorracial, Castel defende que se encontra em curso uma atualização da noção de "classes perigosas". Resgatando aspectos históricos, como a criminalização dos vagabundos na sociedade pré-industrial e os sentimentos de repugnância e medo que o proletariado (miserável e submetido a condições de vida horrorosa) do início do século XIX deflagrava sobre o conjunto da sociedade, Castel destaca que é justamente neste deslocamento dos conflitos sociais para as margens que se configura a utilidade da noção de classe perigosa (p. 68).

Neste caso, conclui o autor, a repressão dessas massas perigosas tem como efeito restaurar a paz da sociedade, sem que os desequilíbrios estruturais sejam evocados. No que tange à insegurança, esta fica reduzida a um problema de delinqüência, a um caso de polícia, esvaziando-se os aspectos estruturantes relacionados à degradação do trabalho e habitação, ao desemprego em massa e à dificuldade de 
convivência entre diferentes grupos étnicos que compartilham o declínio social contemporâneo e a ausência de perspectivas para o futuro.

Assim, vagabundos, proletários e jovens de periferia, amplamente estigmatizados, são discriminados e "empurrados para os confins de uma ordem social na qual não se sentem integrados", carregando, ao mesmo tempo em que ocultam, um mau-funcionamento da sociedade, (seja ela pré-industrial, industrial ou pós-industrial) (p. 71).

Uma vez desvelada a questão do mito e utilidade da noção de classe perigosa, Castel, no capítulo seguinte, nos apresenta um aspecto peculiar desta construção na França, qual seja, o fato de que todo esse processo de estigmatização está atrelado a formas de dominação que provêm de um passado colonialista. Esse instrumentalizou uma concepção do autóctone, que o colocava em uma posição diferente dos demais membros da sociedade, "a "racialização" significando a desvalorização das culturas, qualificadas de autóctones no quadro da relação colonial de dominação “( p. 102).

Castel finaliza, fazendo considerações sobre a ausência de um quadro radical de exclusão social na França, deixando claro, contudo, a existência de grandes desigualdades sociais. Cabe lembrar que essa contextualização histórica das formas excludentes e estigmatizantes desenvolvidas no seio de uma determinada sociedade vem sendo objeto de atenção em seus trabalhos, desde a formulação do conceito de "desfiliação" como um substituto à noção de exclusão (Castel, 1998). Naquele momento, o autor defendia o uso do termo "desfiliação" por dizer respeito à trajetória do sujeito, que, na verdade, não havia sido cortado do social, evitando tanto radicalizar sua situação social, quanto focalizar nas margens um problema originado em outros espaços.

Levando em conta o grande interesse do trabalho de Castel ao entendimento de determinados mecanismos estigmatizantes da sociedade brasileira, é preciso observar as disparidades do caso francês para o brasileiro. No primeiro, apesar dos estigmas, é fato que as populações das periferias contam com proteções contra riscos sociais como no caso de acidentes, doenças, ausência total de recursos - , já no Brasil, há um déficit histórico do que conceitua como cidadania social. Castel destaca como aspecto positivo da sociedade francesa esta obtenção da cidadania social, assinalando que essa levou mais tempo do que a cidadania política para ser implantada, não sendo ainda uma conquista na maior parte dos países.

Apesar das diferenças históricas, a convergência das situações desenvolvidas nas periferias francesa e brasileira pode ser notada na ausência de condições de igualdade do tratamento dos cidadãos, verificando-se, em ambas as sociedades, a ocorrência da discriminação 
negativa, operando em contextos onde o acesso ao trabalho e, em conseqüência, aos bens produzidos é extremamente desigual. Uma desigualdade que por si só compromete a cidadania, pois como Milton Santos (2002) afirma "cada um de nós é mais ou menos consumidor (e, neste caso, também mais ou menos cidadão) em função da acessibilidade concreta aos bens e serviços de uso freqüente e necessário" (p.28).

Por fim, cabe destacar a conclusão de Castel de que, diferentemente dos anos 70, nos dias atuais, na França, os mecanismos de negação, ocultação e discriminação seriam responsáveis, por uma população que, mesmo coberta pela assistência social, não vive mais a esperança de ser reabsorvida pela continuação do progresso econômico e social, e que, portanto, é necessário enfrentar as novas formas de precariedade e desfiliação, sem tratá-las como fenômenos residuais. "Antes que um gueto, a periferia é um canteiro no qual muita coisa deve ser feita, mas igualmente uma realidade que muito nos deve ensinar ainda" (p.114)

\section{Referências Bibliográficas}

CASTEL, Robert. As metamorfoses da questão social. Petrópolis: Vozes, 1998.

CASTEL, Robert. A discriminação negativa: cidadãos ou autóctones? Petrópolis, RJ: Vozes, 2008.

SANTOS, Milton. O país distorcido: o Brasil, a globalização e a cidadania. São Paulo: Publifolha, 2002.

\section{Endereço para correspondência}

Simone da Silva Ribeiro Gomes

Universidade do Estado do Rio de Janeiro- UERJ, Rua São Francisco Xavier, 524, 10

andar Bloco B, Sala 10.002, Maracanã, CEP 20550-900, Rio de Janeiro, RJ, Brasil

Endereço eletrônico: s.ribeirogomes@gmail.com

Ana Lucia Gonçalves Maiolino

Universidade do Estado do Rio de Janeiro - UERJ, Rua São Francisco Xavier, 524, 10 andar Bloco B, Sala 10.002, Maracanã, CEP 20550-900, Rio de Janeiro, RJ, Brasil

Endereço eletrônico: anamaiolino@superig.com.br

Recebido em: 17/02/2008

Aceito para publicação em: 06/03/2009

Acompanhamento do processo editorial: Ana Maria Lopez Calvo Feijoo

\section{Notas}

* Psicóloga formada pela Universidade Federal do Rio de Janeiro - UFRJ

** Doutora em Psicologia Social pelo Programa de Pós-Graduação em Psicologia Social

- PPGPS/UERJ; Coordenadora da pesquisa "Espaço Urbano e Subjetividade: um foco sobre as favelas cariocas". 